\title{
Saponins and Flavonoids from an Infusion of Herniaria hirsuta
}

Authors

Affiliations

Ines van Dooren ${ }^{1}$, Kenn Foubert ${ }^{1}$, Sebastiaan Bijttebier ${ }^{1}$, Mart Theunis ${ }^{1}$, Stefaniya Velichkova ${ }^{1}$, Magda Claeys ${ }^{2}$, Luc Pieters ${ }^{1}$, Vassiliki Exarchou ${ }^{1}$, Sandra Apers ${ }^{1}$

\footnotetext{
${ }^{1}$ Natural Products and Food - Research and Analysis (NatuRA), Department of Pharmaceutical Sciences, University of Antwerp, Antwerp, Belgium

${ }^{2}$ Laboratory for Bio-organic Mass Spectrometry, Department of Pharmaceutical Sciences, University of Antwerp, Antwerp, Belgium
}

\author{
Key words \\ - Herniaria hirsute \\ - Caryophyllaceae \\ - flavonoids \\ - saponins \\ - urolithiasis \\ - cholelithiasis
}

\section{Abstract \\ $\nabla$}

Stone diseases present a major health problem in the Western society, since both urinary and biliary stones occur with a relatively high prevalence of $10-12 \%$ and $10-20 \%$, respectively, and demonstrate a high recurrence rate. At the moment treatment is mainly based on interventional procedures, or prophylactic and dissolution therapy. However, many of the current drugs cause severe side effects, and therefore, there is an increasing interest in natural medicines. At the moment no registered herbal medicinal products are available for treatment of gallstones. Since an infusion of Herniaria hirsuta L. has a proven efficacy against urolithiasis and cholelithiasis, its phytochemical composition has been investigated. Two previously undescribed triterpene saponins, 28$O$ - $\{[\beta$-D-xylopyranosyl- $(1 \rightarrow 4)-\alpha$-L-rhamnopyranosyl-( $1 \rightarrow 2)]-[\beta$-D-glucopyranosyl-(1-6)]- $\beta$-D- glucopyranosyl $\}$-medicagenic acid and 3-O-[ $\alpha$ L-rhamnopyranosyl-( $1 \rightarrow 3)-\beta$-D-glucuronopyranosyl $]-28-O-\{[\beta$-D-glucopyranosyl- $(1 \rightarrow 3)-\beta$-Dxylopyranosyl-(1 $\rightarrow 4)]$-[ $\beta$-D-apiofuranosyl- $(1 \rightarrow$ 3)]- $\alpha$-L-rhamnopyranosyl-( $1 \rightarrow 2)-\beta$-D-fucopyranosyl\}-medicagenic acid and three known flavonoids, quercetin-3-O-(2"-O- $\alpha$-L-rhamnopyranosyl)- $\beta$-D-glucuronopyranoside, rutin, and narcissin (isorhamnetin-3-O-rutinoside), were isolated using flash chromatography and successive semi-preparative HPLC and were well characterized by MS and 1D and 2D NMR spectroscopic techniques. These findings could contribute to the development of a standardized extract that can be used in prophylaxis and treatment of gall and kidney stones.

Supporting information available online at http:// www.thieme-connect.de/products received April 1, 2016

revised October 4, 2016

accepted October 5, 2016

\section{Bibliography}

DOI http://dx.doi.org/

10.1055/s-0042-118710

Published online October 24,

2016

Planta Med 2016; 82:

1576-1583 @ Georg Thieme

Verlag KG Stuttgart - New York ·

ISSN 0032-0943

\section{Correspondence \\ Ines van Dooren}

Natural Products and Food -

Research and Analysis (NatuRA)

Department of Pharmaceutical

Sciences

University of Antwerp

Universiteitsplein 1

2610 Antwerp

Belgium

Phone: + 3232652720

Ines.vanDooren@

uantwerpen.be

\section{Introduction}

\section{$\nabla$}

Both urinary and biliary stones have a relatively high prevalence of about $10-12 \%$ and $10-20 \%$, respectively, in Western society and constitute a major health problem. In addition, the recurrence rate is rather high [1-6]. The treatment of urolithiasis is focused on interventional procedures, such as extracorporeal shock wave lithotripsy (ESWL), ureteroscopy (URS), or percutaneous nephrolithotomy (PNL) on the one hand; and prophylactic, dissolution, and medical expulsion therapy on the other hand. Various drugs are used in these therapies, such as thiazide diuretics, potassium citrate, allopurinol, UroPhos-K (a slow-release potassium phosphate preparation), sodium bicarbonate, D-penicillamine, acetohydroxamic acid, Tham E (an alkalinizing irrigant), alpha-blockers, calcium-channel blockers, and corticosteroids. However, many of these drugs cause severe side effects and up until today no drugs are available for clinical therapy, especially for the prevention and the recurrence of stones [7-9]. The cornerstone of the treatment of gallstone disease consists almost exclusively of cholecystectomy and endoscopic or medical treatment of complications and the use of drugs is still limited [3]. Medical dissolution therapy, mainly based on resolving the cholesterol supersaturation of the bile, is also a potential approach since almost $80 \%$ of the gallstones consist mainly of cholesterol and are caused by saturation of the bile with cholesterol $[3,10,11]$. In this way ursodeoxycholic acid (UDCA) is used to treat patients with moderate symptoms. All these treatments have their specific disadvantages: continuation of pain after cholecystectomy (in 20\% of patients), a slow effect, low efficacy (40\%) and possible stone recurrence for UDCA [12]. At the moment statins and ezetimibe are not yet used against 


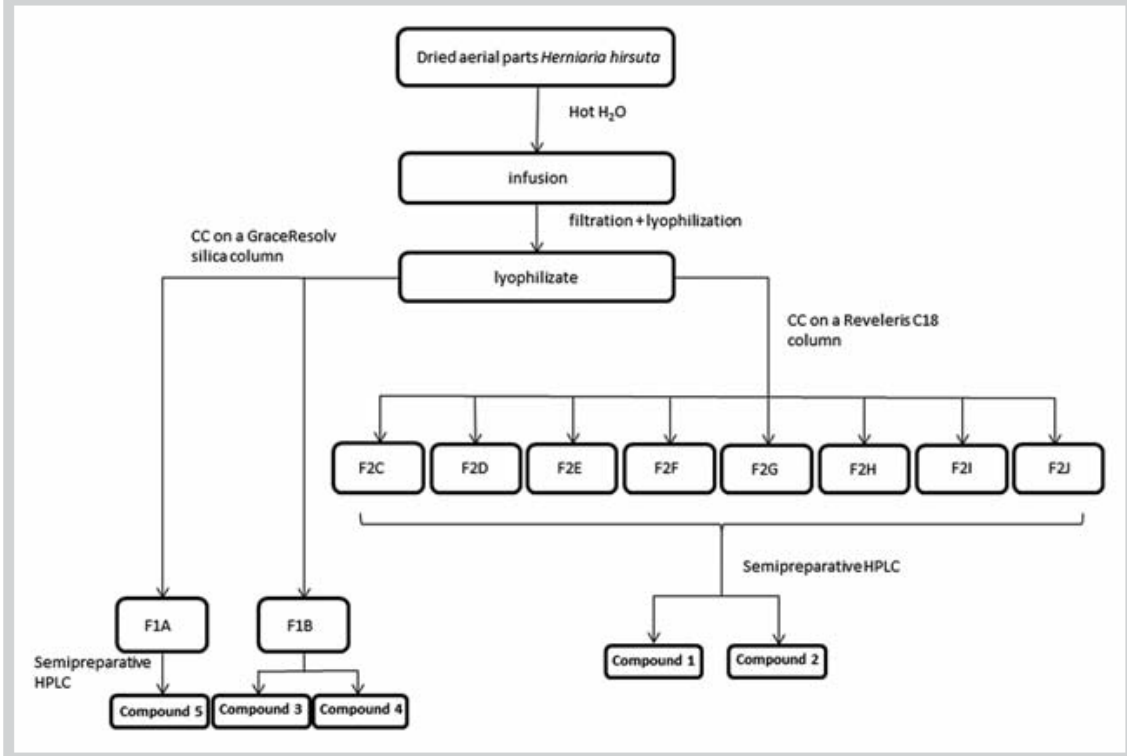

Fig. 1 Extraction scheme.

gallstones because their efficacy should still be proven, although they are well known to lower the hepatic synthesis and/or secretion and/or intestinal absorption of cholesterol and could probably influence the formation of cholesterol-based gallstones and promote their dissolution $[13,14]$.

During the last decades the interest in natural medicines has increased, because usually fewer side effects are expected with herbal medicinal products compared to many synthetic drugs [15]. At the moment no registered herbal product is available for treatment of gallstones.

The genus Herniaria (Caryophyllaceae) contains several species which are widely distributed in Europe, Asia and North-Africa. $H$. glabra, $H$. hirsuta and $H$. fontanesii are traditionally used in Moroccan folk medicine for the treatment of biliary dyskinesia, (uro)lithiasis or as a diuretic. In Europe Herniariae Herba, which can contain $H$. glabra and $H$. hirsuta, is used as a urological drug [16-20]. Some phytochemical research on these species revealed the presence of saponins, flavonoids, and coumarins. While $H$. fontanesii was reported to contain herniariasaponins A-D [21-23], which are bidesmosidic triterpenoid saponins, two monodesmosidic derivatives of medicagenic acid, herniariasaponins $\mathrm{E}$ and $\mathrm{F}$, were isolated from the aerial parts of $H$. hirsuta [19]. Also $H$. glabra contained several mono- and bidesmosidic medicagenic acid derivatives, named herniariasaponins 1-7 [24-27]. Among others, herniarin and umbelliferone were identified as coumarins and quercetin- and isorhamnetin derivatives as flavonoids being present in Herniaria species [28-32].

Since an infusion of $H$. hirsuta has a proven efficacy against urolithiasis and cholelithiasis, this work focuses on the phytochemical characterization of this infusion using semi-preparative HPLC, mass spectrometry and NMR, finally aiming at the development of a standardized extract that can be used in the treatment and prophylaxis of stone diseases [16-18,33].

\section{Results and Discussion}

$\nabla$

Normal phase flash chromatography of $7.3 \mathrm{~g}$ of the dry residue after lyophilization of the infusion of $H$. hirsuta resulted in two fractions of $78 \mathrm{mg}(1 \mathrm{~A})$ and $310 \mathrm{mg}$ (1 B), respectively (○ Fig. 1). Semi-preparative HPLC of fraction $1 \mathrm{~A}$ resulted in the isolation of compound 5 (1.36 mg), whereas semi-preparative HPLC of fraction $1 \mathrm{~B}$ resulted in the isolation of compound $\mathbf{3}(3.5 \mathrm{mg})$ and 4 (1.9 mg). Fractions $2 \mathrm{C}-\mathrm{J}(3.0-38.0 \mathrm{mg})$ yielded compound $\mathbf{1}$ (9.0 mg) and compound 2 (25.5 mg).

Compound 1 ( Fig. 2 ) was obtained as a white amorphous powder. The UV spectrum of 1 showed an absorbance maximum at $194 \mathrm{~nm}$. The HR-ESI-MS mass spectrum showed a molecular ion peak at $m / z 1103.5289[\mathrm{M}-\mathrm{H}]^{-}$and supported a molecular formula of $\mathrm{C}_{53} \mathrm{H}_{84} \mathrm{O}_{24}$. The ESI-MS spectrum of 1 exhibited a pseudo-molecular ion peak at $m / z 1103[\mathrm{M}-\mathrm{H}]^{-}$. The fragmentation patterns are depicted in $\odot$ Fig. 3. The $m / z 1103 \mathrm{MS}^{2}$ product ion spectrum resulted in ion peaks at $m / z 1085$ [M - H-18] $]^{-}, 971$ [M - H-132] $]^{-}, 941$ [M - H-162]-, and 923 [M - H-180] due to the loss of a molecule of water $(18 \mathrm{u})$, a pentose unit $(132 \mathrm{u})$, a hexose unit $(162 \mathrm{u})$, and a hexose unit together with a molecule of water (180 u), respectively. The product ion at $m / z 501[\mathrm{M}-\mathrm{H}-$ 162-132-162-146] $]^{-}$attributed to the loss of two hexoses, a pentose unit, and a deoxyhexose unit $(602 \mathrm{u})$ together with product ions formed at $m / z 483$ [Aglycon-H-18] ${ }^{-}$and 439 [Aglycon-H-18$44]^{-}$was characteristic for medicagenic acid as an aglycon [34]. The $\mathrm{MS}^{3}$ product ion spectrum of $m / z 971[\mathrm{M}-\mathrm{H}-132]^{-}$resulted in a peak at $m / z 809[\mathrm{M}-\mathrm{H}-162]^{-}$due to the loss of a hexose moiety, whereas $\mathrm{MS}^{3}$ analysis of $\mathrm{m} / z 941$ [M-H-162] ${ }^{-}$resulted in a product ion peak at $m / z 747[\mathrm{M}-\mathrm{H}-132-18-44]^{-}$due to the loss of a pentose moiety together with a water and a carbon dioxide molecule. The formation of these latter $\mathrm{MS}^{3}$ product ions together with the MS ${ }^{2}$ spectra indicated that both residues were in a terminal position, suggesting the presence of a branched sugar chain.

The monosaccharides obtained after acidic hydrolysis of compound 1 were identified as D-glucose, D-xylose, and L-rhamnose by GC-MS [35] (see Materials and Methods).

The ${ }^{1} \mathrm{H}-\mathrm{NMR}$ and ${ }^{13} \mathrm{C}$-NMR spectra of the aglycon part of compound 1 displayed six tertiary methyl signals at $\delta_{\mathrm{H}} 0.80(\mathrm{H}-26)$, 0.91 (H-29), 0.94 (H-30), $1.16(\mathrm{H}-27), 1.291(\mathrm{H}-25)$, and $1.33(\mathrm{H}-$ 24) giving correlations in HSQC with $\delta_{\mathrm{C}} 18.3$ (C-26), 33.7 (C-29), 24.4 (C-30), 26.4 (C-27), 17.9 (C-25), and 13.3 (C-24), an olefinic proton at $\delta_{\mathrm{H}} 5.29(\mathrm{H}-12)$, two olefinic carbons at $\delta_{\mathrm{C}} 123.7(\mathrm{C}-12)$ and $145.0(\mathrm{C}-13)$ and two oxygen bearing methine protons at $\delta_{\mathrm{H}}$ $3.98(\mathrm{H}-3)$ and $4.08(\mathrm{H}-2)$ ( Table 1). Furthermore, a downfield shifted signal at $\delta_{\mathrm{C}} 182.4(\mathrm{C}-23)$ and an upfield shifted carbon sig- 
nal at $\delta_{\mathrm{C}} 178.2(\mathrm{C}-28)$ suggested the presence of a carboxylic acid and an ester function, respectively. Thorough 1D and 2D NMR spectroscopic analysis confirmed the structure of the aglycon to be medicagenic acid ( $2 \beta, 3 \beta$-dihydroxyolean-12-ene-23,28-dioic acid). These findings were in accordance with the results obtained with ESI-MS experiments and with previously published data $[19,22,24,36]$. The presence of an upfield shifted carbon signal (C-28) at $\delta_{\mathrm{C}} 178.2$ suggested compound 1 to be a monodesmosidic saponin. Four anomeric proton signals at $\delta_{\mathrm{H}} 5.44(\mathrm{~d}, J=$ $1.5 \mathrm{~Hz}$; Rha H-1), 5.38 (d, $J=7.6 \mathrm{~Hz}$; Glcl H-1), 4.42 (d, $J=7.6$; Xyl $\mathrm{H}-1$ ), and 4.34 (d, $J=7.7$; GlcII $\mathrm{H}-1$ ) displaying correlations in the HSQC spectrum with four anomeric carbon signals at $\delta_{\mathrm{C}} 101.3$ (Rha C-1), 95.2 (GlcI C-1), 107.6 (Xyl C-1), and 104.9 (GlcII C-1), respectively, evidenced the presence of four sugar moieties. The complete assignment of the monosaccharides residues was performed by COSY, TOCSY, HSQC, and HMBC experiments and GC-MS analysis. This led to the identification of two $\beta$-D-glucopyranose moieties (GlcI and GlcII), a $\beta$-D-xylopyranose (Xyl) and a $\alpha$-L-rhamnopyranose unit (Rha) ( Table 1 ). The $\beta$-anomeric configuration of the glucopyranosyl and xylopyranosyl moiety and the $\alpha$-anomeric configuration of the rhamnopyranosyl moiety were confirmed by the large $J_{\mathrm{H} 1, \mathrm{H} 2}$ coupling constants of 7$8 \mathrm{~Hz}$ and $1.5 \mathrm{~Hz}$, respectively. The $\alpha$-anomeric configuration was confirmed by comparison with the ${ }^{13} \mathrm{C}$ NMR values of methyl $\alpha$ L-rhamnoside and methyl $\beta$-L-rhamnoside published by Agrawal et al. [37].

The HMBC cross peaks at $\delta_{\mathrm{H}} / \delta_{\mathrm{C}} 5.44$ (Rha H-1)/76.7 (GlcI C-2), 4.42 (Xyl H-1)/84.9 (Rha C-4), and 4.34 (GlcII H-1)/69.7 (GlcI C$6)$ suggested the sequence of the oligosaccharide moiety at C-28 to be [Xyl-( $1 \rightarrow 4)$-Rha- $(1 \rightarrow 2)]$-[GlcII- $(1 \rightarrow 6)]$-GlcI-. Therefore, compound 1 could finally be elucidated as $28-0-\{[\beta$-D-xylopyra$\operatorname{nosyl}(1 \rightarrow 4)$ - $\alpha$-L-rhamnopyranosyl $(1 \rightarrow 2)]-[(\beta$-D-glucopyranoside- $(1 \rightarrow 6)]-\beta$-D-glucopyranosyl $\}$-medicagenic acid, for which the name herniariasaponin $\mathrm{G}$ was adopted ( Figs. 2 and $\mathbf{3}$ ).

Compound 2 ( $\odot$ Fig. 2) was obtained as a white amorphous powder. The UV spectrum of compound $\mathbf{2}$ showed an absorbance maximum at $196 \mathrm{~nm}$. The HR-ESI-MS mass spectrum showed a molecular ion peak at $m / z 1541.6649[\mathrm{M}-\mathrm{H}]^{-}$and supported a molecular formula of $\mathrm{C}_{70} \mathrm{H}_{110} \mathrm{O}_{37}$. ESI-MS of 2 exhibited a pseudo-molecular ion peak at $m / z 1541[\mathrm{M}-\mathrm{H}]^{-}$. The fragmentation patterns are depicted in Fig $\diamond$. The MS 2 product ion spectrum of $m / z 1541$ resulted in ion peaks at $m / z 1523$ [M - H-18]-, 1395 $[\mathrm{M}-\mathrm{H}-146]^{-}$, and $1379[\mathrm{M}-\mathrm{H}-162]^{-}$, which indicated the presence of a terminal deoxyhexose and hexose moiety. Other product ions were generated at $m / z 1219$ [M - H-146-176]-, 1201 [M - H-146-176-18], 1157 [M - H-146-176-18-44], 1087 [M - H-146-176-132], 1057 [M - H-146-176-162]-, 925 [M H-146-176-162-132] $]^{-}, 823$ [M - H-162+132+132+146+146] $]^{-}$, and $717[162+132+132+146+146-\mathrm{H}]^{-}$. The $\mathrm{MS}^{3}$ product ion spectrum of $m / z 1395[\mathrm{M}-\mathrm{H}-146]^{-}$resulted in ion peaks at $m / z$ $1377\left[\mathrm{M}-\mathrm{H}_{-} \mathrm{H}_{2} \mathrm{O}\right]^{-}, 1219$ [M - H-176] $]^{-}$, and 1157 [M - H-176$18-44]^{-}$, suggesting a hexuronic moiety attached to a terminal deoxyhexose unit. MS ${ }^{3}$ analysis of $m / z 1219$ [M - H-146-176] $]^{-}$resulted in product ion peaks at $m / z 1201\left[\mathrm{M}-\mathrm{H}-\mathrm{H}_{2} \mathrm{O}\right]^{-}, 1087[\mathrm{M}-$ H-132] $]^{-}, 1057$ [M - H-162], 925 [M - H-162-132], 717 $[162+132+132+146+146-\mathrm{H}]^{-}, \quad 501 \quad[\mathrm{M}-\mathrm{H}-146-176-162-$ 132-132-146-146] $]^{-}$, and 483 [Aglycon- $\left.\mathrm{H}_{-1} \mathrm{H}_{2} \mathrm{O}\right]^{-} . \mathrm{MS}^{3}$ analysis of $\mathrm{m} / \mathrm{z} 1087$ [M - H-146-176-132] $]^{-}$resulted in product ion peaks at $m / z 1069$ [M - H- $\left.{ }_{2} \mathrm{O}\right]^{-}, 925$ [M - H-162] $]^{-}$, and 501 [M - H-146176-162-132-132-146-146] $]^{-}$, whereas $\mathrm{MS}^{3}$ analysis of $m / z$ 1057 [M - H-146-176-162 $]^{-}$resulted in product ion peaks at m/z 925 [M - H-132]-, 647 [M - H-146-176-162-132-132-

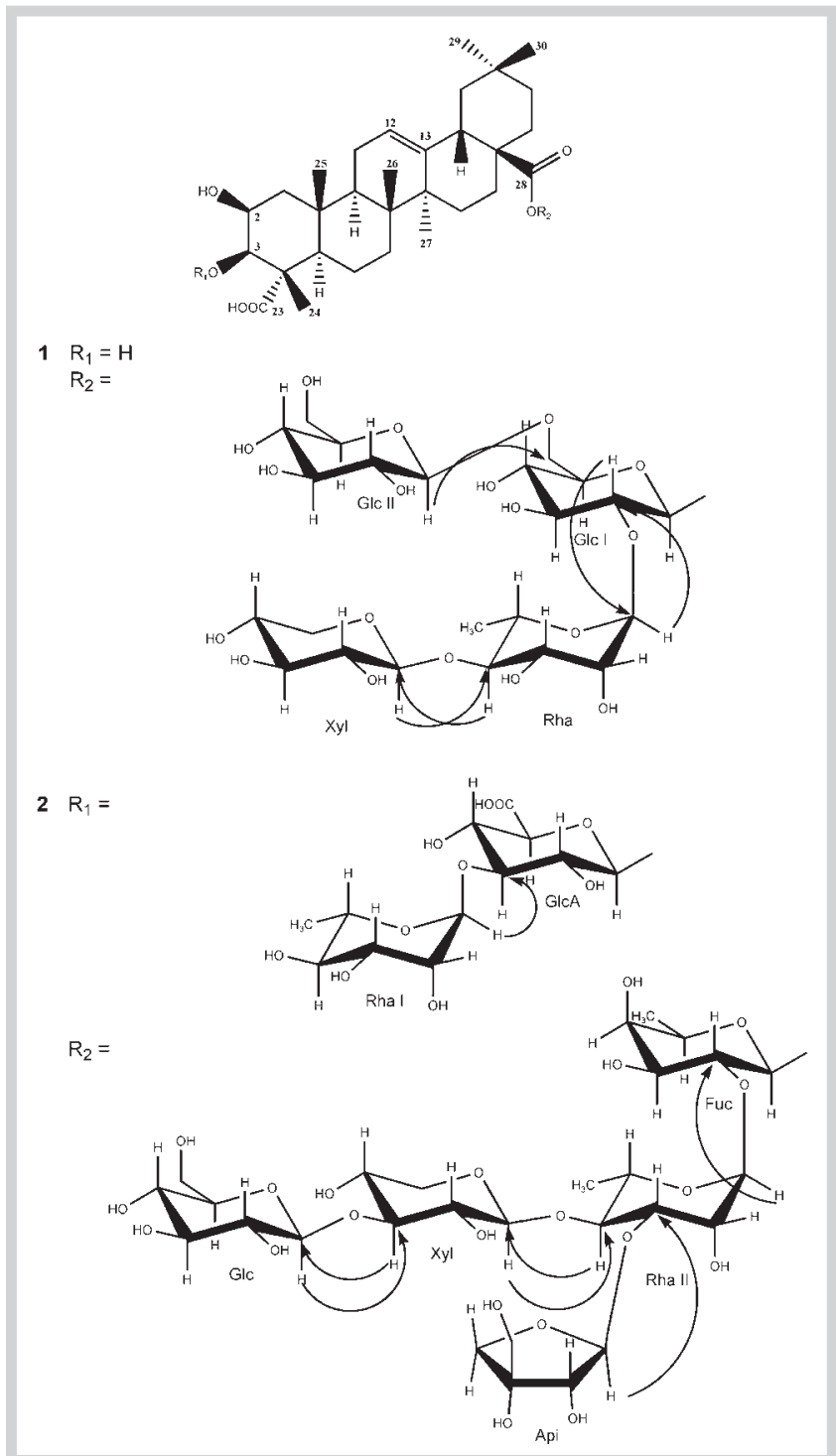

Fig. 2 Chemical structure of compounds $\mathbf{1}$ and $\mathbf{2}$ including key HMBC correlations.

146] $]^{-}, 629$ [M - H-146-176-162-132-132-146-18]', and 501 [M - H-146-176-162-132-132-146-146] $]^{-}$. The formation of product ions at $m / z 1087$ and $m / z 1057$, formed by the loss of a pentose and a hexose residue, respectively, together with their MS $^{3}$ spectra, showing a loss of a hexose for the ion at $\mathrm{m} / \mathrm{z} 1087$ and a loss of a pentose for the ion at $\mathrm{m} / \mathrm{z} 1057$, indicated that both residues are in a terminal position, indicating that the sugar chain was most probably branched. The $\mathrm{MS}^{3}$ product ion spectrum of $m / z 925$ revealed peaks at $m / z 501$ [M - H-146-176-162-132132-146-146] $]^{-}$and 483 [Aglycon- H- $\left._{2} \mathrm{O}\right]^{-}$.

GC-MS analysis of the trimethylsilylated monosaccharides obtained after acidic hydrolysis of compound 2, resulted in the identification of D-glucose, D-xylose, D-fucose, L-rhamnose, and D-glucuronic acid (see Materials and Methods).

The ${ }^{1} \mathrm{H}-\mathrm{NMR}$ and ${ }^{13} \mathrm{C}-\mathrm{NMR}$ chemical shifts of the aglycon part of compound $\mathbf{2}$ ( Table 1) were similar to those of compound $\mathbf{1}$ indicating that the same aglycon was present. The presence of an upfield shifted carbon signal and a deshielded carbon signal, respectively, at $\delta_{\mathrm{C}} 178.2(\mathrm{C}-28)$ and $\delta_{\mathrm{C}} 86.7$ (C-3) suggested compound 2 to be a bidesmosidic saponin. Seven anomeric proton 
signals at $\delta_{\mathrm{H}} 5.37(\mathrm{~d}, J=1.21 \mathrm{~Hz})$ (RhaII $\left.\mathrm{H}-1\right), \delta_{\mathrm{H}} 5.35(\mathrm{~d}, J=$ $8.15 \mathrm{~Hz})\left(\right.$ Fuc H-1), $\delta_{\mathrm{H}} 5.24$ (d, $\left.J=3.79\right)\left(\right.$ Api H-1), $\delta_{\mathrm{H}} 5.19(\mathrm{~d}, J=$ $1.11 \mathrm{~Hz})\left(\right.$ Rhal H-1), $\delta_{\mathrm{H}} 4.63(\mathrm{~d}, J=7.74)(\mathrm{Xyl} \mathrm{H}-1), \delta_{\mathrm{H}} 4.58(\mathrm{~d}, J=$ 7.84) (Glc H-1), and $\delta_{\mathrm{H}} 4.39$ (d, $J=7.62 \mathrm{~Hz}$ ) (GlcA H-1) displaying correlations in the HSQC spectrum with seven anomeric carbon signals at $\delta_{\mathrm{C}} 101.5$ (Rhall C-1), 95.4 (Fuc C-1), 112.0 (Api C-1), 102.4 (Rhal C-1), 105.12 (Xyl C-1), 105.3 (Glc C-1), and 105.09 (GlcA C-1), respectively, evidenced the presence of seven sugar moieties. They were identified, using the same techniques as for compound 1, as $\beta$-D-glucopyranosyl (Glc), $\beta$-D-xylopyranosyl (Xyl), $\alpha$-L-rhamnopyranosyl (RhaI and RhaII), $\beta$-D-apiofuranosyl (Api), and $\beta$-D-fucopyranosyl (Fuc) moieties. The $\beta$-anomeric configuration of the Glc, Xyl, Api, Fuc, and GlcA moiety was confirmed by the large $J_{\mathrm{H} 1}$, H2 coupling constants of $7-8 \mathrm{~Hz}$, respectively. The coupling constants of $1.1-1.2 \mathrm{~Hz}$ confirmed the $\alpha$ anomeric configuration of the rhamnopyranosyl moiety. This $\alpha$ anomeric configuration was also confirmed by comparison with the ${ }^{13} \mathrm{C}$ NMR values of methyl $\alpha$-L-rhamnoside and methyl $\beta$-Lrhamnoside published by Agrawal et al. [37].

Linkages between both the aglycon and sugar units were mainly achieved by HMBC and are shown in $\odot$ Fig. 2. A cross-peak in the HMBC spectrum from C-3 of the aglycon at $\delta_{\mathrm{C}} 86.7$ to the anomeric proton at $\delta_{\mathrm{H}} 4.39$ (GlcA H-1) indicated the linkage position of the $\beta$-D-glucuronic acid moiety. The downfield shifted signal of GlcA C-3 at $\delta_{\mathrm{C}} 82.7$ giving a HMBC correlation with the anomeric proton of Rhal at $\delta_{\mathrm{H}} 5.19$, suggested a substitution at this position. The chemical shifts of Rhal ( Table 1 ) were those of a terminal Rha. Thus, the glycan part at C-3 of the aglycon was identified as Rha- $(1 \rightarrow 3)$-GlcA-.

A deshielded signal of the anomeric proton of Fuc at $\delta_{\mathrm{H}} 5.35$ giving a correlation in the HSQC spectrum with a shielded anomeric carbon signal at $\delta_{C} 95.4$ indicated the linkage of Fuc to the $\mathrm{C}-28$ position of the aglycon through an ester linkage. A HMBC cross peak between $\delta_{\mathrm{H}} 5.35$ (Fuc $\mathrm{H}-1$ ) and $\delta_{\mathrm{C}} 178.2(\mathrm{C}-28)$ confirmed this finding. A cross-peak in COSY from Fuc $\mathrm{H}-1\left(\delta_{\mathrm{H}} 5.35\right)$ to Fuc $\mathrm{H}-2$ $\left(\delta_{\mathrm{H}} 3.82\right)$ giving a correlation in the HSQC spectrum to Fuc C-2 $\left(\delta_{\mathrm{C}}\right.$ 74.9) together with long-range peaks in the HMBC spectrum between $\delta_{\mathrm{C}} 101.5$ (RhaII C-1) and $\delta_{\mathrm{H}} 3.82$ (Fuc H-2) and between the anomeric proton signal of Rhall at $\delta_{\mathrm{H}} 5.37$ and Fuc C $-2\left(\delta_{\mathrm{C}}\right.$ 74.9) suggested a substitution at position 2 of Fuc with Rhall. The presence of two deshielded carbon signals of Rhall at C-3 $\left(\delta_{\mathrm{C}} 81.6\right)$ and RhaII $\mathrm{C}-4\left(\delta_{\mathrm{C}} 79.2\right)$ showing HMBC correlations with anomeric protons at $\delta_{\mathrm{H}} 5.24$ (Api H-1) and $\delta_{\mathrm{H}} 4.63$ (Xyl H-1), respectively, revealed a disubstitution of RhaII by Api at C-3 and Xyl at C-4. This was confirmed by a reverse correlation at $\delta_{\mathrm{H}} / \delta_{\mathrm{C}} 3.65$ (Rha H-4)/ 105.1 (Xyl C-1). The ${ }^{1} \mathrm{H}$ and ${ }^{13} \mathrm{C}$ NMR signals assigned by 2D NMR spectroscopic analysis were those of a terminal Api and Xyl [38]. The HMBC correlation at $\delta_{\mathrm{H}} / \delta_{\mathrm{C}} 4.58$ (Glc H-1)/88.2 (Xyl C-3) and the reverse correlation at $\delta_{\mathrm{H}} / \delta_{\mathrm{C}} 3.47(\mathrm{Xyl} \mathrm{H}-3) / 105.3$ (Glc C-1) indicated a $1 \rightarrow 3$ linkage between Glc and Xyl. Thus the oligosaccharide moiety at C-28 was identified as [Glc-( $1 \rightarrow 3)$-Xyl$(1 \rightarrow 4)]$-[Api- $(1 \rightarrow 3)]$-Rha- $(1 \rightarrow 2)$-Fuc-. On the basis of the above results, compound 2 was finally elucidated as 3-0-[ $\alpha$-L-rhamnopyranosyl- $(1 \rightarrow 3)-\beta$-D-glucuronopyranosyl]-28- 0 - $\{[\beta$-D-glucopyranosyl-( $1 \rightarrow 3)$ - $\beta$-D-xylopyranosyl- $(1 \rightarrow 4)]$-[ $\beta$-D-apiofuranosyl-( $1 \rightarrow 3)$ ]- $\alpha$-L-rhamnopyranosyl-( $1 \rightarrow 2)-\beta$-D-fucopyranosyl $\}$ medicagenic acid, for which the name herniariasaponin $\mathrm{H}$ was adopted ( $\odot$ Figs. 2 and $\mathbf{4}$ ).

Furthermore, three known flavonoids were isolated from the infusion of $H$. hirsuta and identified as quercetin-3-O-(2"-O- $\alpha$-Lrhamnopyranosyl)- $\beta$-D-glucuronopyranoside (3), rutin (4), and narcissin (5) $[28,39]$.

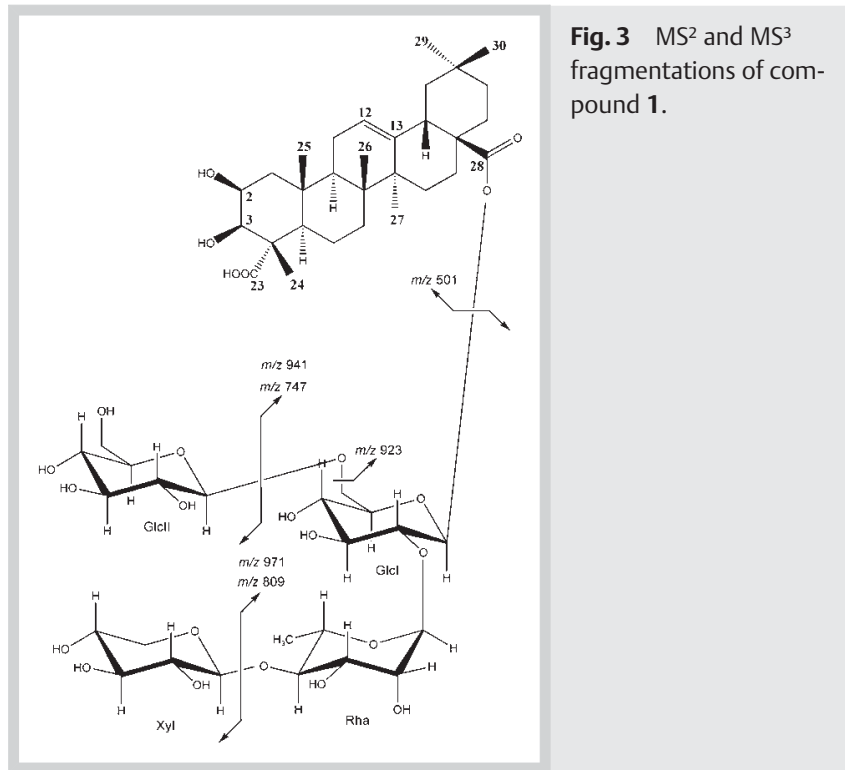

The majority of saponins of the Caryophyllaceae contains as aglycone gypsogenic acid, gypsogenin, or quillaic acid. Saponins containing medicagenic acid as aglycon such as herniariasaponins are less frequently found [40]. To the best of our knowledge, until now thirteen herniariasaponins have been reported, from which only from Herniaria hirsuta, i.e. herniariasaponin E and herniariasaponin F [19]. Other herniariasaponins were also found in other species: herniariasaponins A-D were already reported from Herniaria fontanesii and herniariasaponins 1-7 were found in Herniaria glabra [21-27]. Compounds 1 and 2, for which the name herniariasaponin $\mathrm{G}$ and $\mathrm{H}$, respectively, has been adopted, are reported here for the first time from nature. Both compounds $\mathbf{1}$ and $\mathbf{2}$ have medicagenic acid as aglycon, which is next to 16-hydroxymedicagenic acid one of the two aglycons found in herniariasaponins. Compound $\mathbf{1}$ is a monodesmosidic saponin which differs from herniariasaponin $\mathrm{E}$ by the absence of an acetylgroup in position 2 of the aglycon. Saponin $\mathbf{2}$ is a bidesmosidic saponin containing seven sugar moieties, one more than all other herniariasaponins found in nature, and is the largest herniariasaponin found until now. It also contains apiose as a sugar moiety, which is present as well in herniariasaponins 5 and 7.

Herniariae herba was reported to contain quercetin- and isorhamnetin derivatives such as narcissin and rutin [28,29,31]. In addition, narcissin (isorhametin-3-O-rutinoside) was isolated from Herniaria glabra, isorhamnetin 3-[3"'-feruloylrhamnosyl$(1 \rightarrow 6)$-galactoside], isorhamnetin 3-robinobioside and catechin were discovered in Herniaria fontanesii, and rhamnazin 3-rutinoside in Herniaria ciliolata [30,32]. To the best of our knowledge, this is the first time that quercetin-3-O-(2"-O- $\alpha$-L-rhamnopyranosyl)- $\beta$-D-glucuronopyranoside was isolated from Herniaria hirsuta.

Compounds 1-5 isolated during the present work constitute the main peaks in the chromatographic profile of the infusion of Herniaria hirsuta (Fig. S1, Supporting Information), proven to have a cholesterol lowering effect in the gall bladder of dogs [33]. Since the infusion is now fully characterized, it will be possible to develop a standardized herbal medicinal product that may be used in the treatment of gall and kidney stones. Other plant species containing medicagenic acid derivatives could possibly have a positive effect on gallstones, on the assumption that the saponins are the active constituents. 
Table $1{ }^{1} \mathrm{H}$ NMR and ${ }^{13} \mathrm{C}$ NMR assignments of compounds 1 and 2. [ $\delta$ (ppm), J in $\mathrm{Hz}, \mathrm{CD}_{3} \mathrm{OD}, 400 \mathrm{MHz}$ for ${ }^{1} \mathrm{H}$ and $100 \mathrm{MHz}$ for ${ }^{13} \mathrm{C}$ ].

\begin{tabular}{|c|c|c|c|c|c|}
\hline \multicolumn{3}{|l|}{ (1) } & \multicolumn{3}{|l|}{ (2) } \\
\hline Aglycon & $\delta_{c}$ & $\delta_{\mathrm{H}}$ & Aglycon & $\delta_{C}$ & $\delta_{\mathrm{H}}$ \\
\hline 1 & 45.8 & $2.11,1.221, \mathrm{~m}$ & 1 & 45.1 & $2.10,1.25, \mathrm{~m}$ \\
\hline 2 & 72.2 & $4.08, \mathrm{~m}$ & 2 & 71.0 & $4.31, \mathrm{~d}(J=2.3)$ of $\mathrm{br} \mathrm{s}$ \\
\hline 3 & 76.6 & $3.98, d(3.8)$ & 3 & 86.7 & $4.07, \mathrm{~m}$ \\
\hline 4 & 54.3 & & 4 & 53.6 & \\
\hline 5 & 53.0 & $1.586, \mathrm{~m}$ & 5 & 53.3 & $1.59, \mathrm{~m}$ \\
\hline 6 & 22.2 & $1.65,1.17, \mathrm{~m}$ & 6 & 21.8 & $1.57,1.20, \mathrm{~m}$ \\
\hline 7 & 33.9 & $1.49,1.38, \mathrm{~m}$ & 7 & 34.0 & $1.51,1.38, \mathrm{~m}$ \\
\hline 8 & 41.2 & & 8 & 41.2 & \\
\hline 9 & 49.9 & $1.585, \mathrm{~m}$ & 9 & 49.8 & $1.58, \mathrm{~m}$ \\
\hline 10 & 37.6 & & 10 & 37.6 & \\
\hline 11 & 24.8 & $2.02,1.93, \mathrm{~m}$ & 11 & 24.1 & $2.05,1.62, \mathrm{~m}$ \\
\hline 12 & 123.7 & $5.29, \mathrm{t}(3.2)$ & 12 & 123.8 & $5.27, \mathrm{t}(3.4)$ \\
\hline 13 & 145.0 & & 13 & 144.8 & \\
\hline 14 & 43.3 & & 14 & 43.3 & \\
\hline 15 & 29.4 & $1.55,1.219, \mathrm{~m}$ & 15 & 29.2 & $1.63,1.197, \mathrm{~m}$ \\
\hline 16 & 24.1 & $2.06,1.63, \mathrm{~m}$ & 16 & 24.8 & $1.99,1.91, \mathrm{~m}$ \\
\hline 17 & 50.2 & & 17 & 48.1 & \\
\hline 18 & 42.9 & $2.82, \mathrm{dd}(14.0,3.8)$ & 18 & 43.1 & $2.83, \mathrm{dd}(14.0,4.0)$ \\
\hline 19 & 47.5 & $1.715,1.14, \mathrm{~m}$ & 19 & 47.4 & $1.73,1.14, \mathrm{~m}$ \\
\hline 20 & 31.7 & & 20 & 31.7 & \\
\hline 21 & 35.0 & $1.40,1.23, \mathrm{~m}$ & 21 & 35.0 & $1.39,1.23, \mathrm{~m}$ \\
\hline 22 & 33.2 & $1.723,1.57, \mathrm{~m}$ & 22 & 33.2 & $1.76,1.57, \mathrm{~m}$ \\
\hline 23 & 182.4 & & 23 & 182.4 & \\
\hline 24 & 13.3 & $1.33, \mathrm{~s}$ & 24 & 13.9 & $1.39, \mathrm{~s}$ \\
\hline 25 & 17.9 & $1.291, \mathrm{~s}$ & 25 & 17.3 & $1.27, \mathrm{~s}$ \\
\hline 26 & 18.3 & $0.80, \mathrm{~s}$ & 26 & 17.9 & $0.80, \mathrm{~s}$ \\
\hline 27 & 26.4 & $1.16, \mathrm{~s}$ & 27 & 26.5 & $1.17, \mathrm{~s}$ \\
\hline 28 & 178.2 & & 28 & 178.2 & \\
\hline 29 & 33.7 & $0.91, \mathrm{~s}$ & 29 & 33.6 & $0.91, \mathrm{~s}$ \\
\hline 30 & 24.4 & $0.94, \mathrm{~s}$ & 30 & 24.3 & $0.93, \mathrm{~s}$ \\
\hline $\mathrm{Glcl}$ & & & GlcA & & \\
\hline 1 & 95.2 & $5.38, d(7.6)$ & 1 & 105.09 & 4.39, $d(J=7.6)$ \\
\hline 2 & 76.7 & $3.62, \mathrm{~m}$ & 2 & 75.9 & $3.39, \mathrm{~m}$ \\
\hline 3 & 79.4 & $3.56, \mathrm{~m}$ & 3 & 82.7 & $3.55, \mathrm{~m}$ \\
\hline 4 & 71.1 & $3.47, \mathrm{~m}$ & 4 & 72.3 & $3.51, \mathrm{~m}$ \\
\hline 5 & 77.8 & $3.49, \mathrm{~m}$ & 5 & 76.6 & $3.71, \mathrm{~m}$ \\
\hline 6 & 69.7 & $4.10,3.76 \mathrm{~d}(10.8) ; \mathrm{dd}(11.8 ; 4.92)$ & 6 & 175.7 & \\
\hline Rha & & & Rhal & & \\
\hline 1 & 101.3 & 5.44, brs $(1.5)$ & 1 & 102.4 & $5.19, \mathrm{brs}(J=1.1)$ \\
\hline 2 & 72.0 & $3.95, \mathrm{~m}$ & 2 & 72.5 & $3.92, \mathrm{~m}$ \\
\hline 3 & 72.4 & $3.845, \mathrm{~m}$ & 3 & 72.4 & $3.70, \mathrm{~m}$ \\
\hline 4 & 84.9 & $3.51, \mathrm{~m}$ & 4 & 74.3 & $3.36, \mathrm{~m}$ \\
\hline 5 & 68.9 & $3.82, \mathrm{~m}$ & 5 & 69.9 & $4.07, \mathrm{~m}$ \\
\hline 6 & 17.5 & $1.285, \mathrm{~s}$ & 6 & 18.0 & $1.23, \mathrm{~s}$ \\
\hline Xyl & & & Fuc & & \\
\hline 1 & 107.6 & $4.42, d(7.6)$ & 1 & 95.4 & 5.35, $d(J=8.2)$ \\
\hline 2 & 76.4 & $3.181, \mathrm{~m}$ & 2 & 74.9 & $3.82, \mathrm{~m}$ \\
\hline 3 & 78.5 & $3.31, \mathrm{~m}$ & 3 & 76.6 & $3.71, \mathrm{~m}$ \\
\hline 4 & 71.3 & $3.45, \mathrm{~m}$ & 4 & 73.8 & $3.57, \mathrm{~m}$ \\
\hline 5 & 67.4 & $3.84,3.178, \mathrm{~m}$ & 5 & 72.8 & $3.69, \mathrm{~m}$ \\
\hline Glcll & & & 6 & 16.7 & $1.22, \mathrm{~s}$ \\
\hline 1 & 104.9 & $4.34, d(7.7)$ & Rhall & & \\
\hline 2 & 75.3 & $3.20, \mathrm{~m}$ & 1 & 101.5 & $5.37, \operatorname{brs}(J=1.2)$ \\
\hline 3 & 78.1 & $3.37, \mathrm{~m}$ & 2 & 72.1 & $4.088, \mathrm{~m}$ \\
\hline 4 & 71.7 & $3.30, \mathrm{~m}$ & 3 & 81.6 & $3.84, \mathrm{~m}$ \\
\hline 5 & 78.1 & $3.24, \mathrm{~m}$ & 4 & 79.2 & $3.65, \mathrm{~m}$ \\
\hline \multirow[t]{8}{*}{6} & 62.9 & $3.850,3.67, \mathrm{~m}$ & 5 & 68.8 & $3.86, \mathrm{~m}$ \\
\hline & & & 6 & 18.6 & $1.24, \mathrm{~s}$ \\
\hline & & & Api & & \\
\hline & & & 1 & 112.0 & $5.24, d(J=3.8)$ \\
\hline & & & 2 & 78.3 & 4.03, $d(J=3.9)$ \\
\hline & & & 3 & 80.2 & \\
\hline & & & 4 & 74.9 & $4.091, \mathrm{~m} / 3.76, \mathrm{~d}(\mathrm{~J}=9.7)$ \\
\hline & & & 5 & 65.2 & $3.58, \mathrm{~s}$ \\
\hline
\end{tabular}


Table 1 Continued

\begin{tabular}{|c|c|c|c|c|}
\hline (1) & & (2) & & \\
\hline Aglycon & $\begin{array}{ll}\delta_{C} & \delta_{H}\end{array}$ & Aglycon & $\delta_{\mathrm{C}}$ & $\delta_{\mathrm{H}}$ \\
\hline & & Xyl & & \\
\hline & & 1 & 105.12 & $4.63, \mathrm{~d}(\mathrm{~J}=7.7)$ \\
\hline & & 2 & 75.3 & $3.33, \mathrm{~m}$ \\
\hline & & 3 & 88.2 & $3.47, \mathrm{~m}$ \\
\hline & & 4 & 70.2 & $3.59, \mathrm{~m}$ \\
\hline & & 5 & 66.7 & $3.90, \mathrm{~m} / 3.20, \mathrm{~m}$ \\
\hline & & Glc & & \\
\hline & & 1 & 105.3 & $4.58, d(J=7.8)$ \\
\hline & & 2 & 75.5 & $3.35, \mathrm{~m}$ \\
\hline & & 3 & 77.8 & $3.46, \mathrm{~m}$ \\
\hline & & 4 & 78.3 & $3.34, \mathrm{~m}$ \\
\hline & & 5 & 71.6 & $3.30, \mathrm{~m}$ \\
\hline & & 6 & 62.8 & $3.88, \mathrm{~m} / 3.66, \mathrm{~m}$ \\
\hline
\end{tabular}

\section{Material and Methods}

$\nabla$

\section{Reagents and standards}

Methanol HPLC grade and acetonitrile Far UV HPLC grade were obtained from Fisher Scientific. Butanol (99\%), formic acid (99+ $\%$ ), acetic acid (99.8\%), sulphuric acid 85\% (g/g) and ethylacetate HPLC grade were provided by Acros. Hederacoside C (98.19\% purity and $97.70 \%$ purity) was obtained from Extrasynthese and Carl Roth $\mathrm{GmbH}$, herniarin (>98\% purity) from Carl Roth, $\alpha$-hederin (99.35\% purity) from Extrasynthese, and rutin (99.70\% purity) from Extrasynthese and from Sigma (96\% purity). p-Anisaldehyde,

L-(+) arabinose (min. 99\%), L-rhamnose monohydrate (min. 99\%), D-ribose (min. 99\%), D-(+)-glucose ( $\geq 99.5 \%), \alpha$-fructose (min. 99\%), L-(-)-fucose ( $\geq 99 \%)$ D-(+)-galacturonic acid, and L-(-)-xylose (min. 99\%) were obtained from Sigma Aldrich, BSTFA $+1 \%$ TMCS from Thermo Scientific, pyridine (99+\%), D-(+)-mannose (99+\%), D-(+)-galactose, and glucuronic acid (98\%) from Acros.

\section{Plant material}

Aerial parts from Herniaria hirsuta were collected in d'Oujda, Morocco. A voucher specimen of the plant is kept at the Muséum National d'Histoire Naturelle - Institut Scientifique-Université Mohamed V Agdal (Reference number: 5902).

\section{Extraction and isolation}

The material was air dried. The aqueous infusions of Herniaria hirsuta were prepared from $80 \mathrm{~g}$ in $4 \mathrm{~L}$ of boiling water as previously described [18]. The infusions were cooled, portions were combined, filtered, and lyophilized. Typically, $100 \mathrm{~g}$ of plant material yielded about $15 \mathrm{~g}$ lyophilizate.

Column chromatography: To obtain pure compounds of $H$. hirsuta, the infusion was first subjected to column chromatography. The separation was performed using a Gilson 306-pump coupled to a normal phase GraceResolv column (150 g, 40-63 $\mu \mathrm{m}$ ) and the sample was applied on top ( $7.3 \mathrm{~g}$ ). Elution of the column was performed subsequently with dichloromethane, ethyl acetate and methanol. Fractions were collected in volumes of $30 \mathrm{~mL}$. Subsequently reversed phase flash chromatography was carried out using a Reveleris Flash Chromatography system equipped with a Reveleris C18 column ( $40 \mathrm{~g}, 40 \mu \mathrm{m})$. Compounds were eluted with water and methanol using the following gradient: Solvent A: $\mathrm{H}_{2} \mathrm{O}$, solvent B: $\mathrm{CH}_{3} \mathrm{OH}$ : $5 \%$ B for $8 \mathrm{~min}$, from $5 \%$ to $100 \% \mathrm{~B}$ in
$82 \mathrm{~min}, 100 \%$ B for $5 \mathrm{~min}$; fractions of $25 \mathrm{~mL}$ were collected. All fractions were monitored by thin layer chromatography (TLC). Every fraction was applied on a normal phase-TLC plate (NPTLC; $20 \times 20 \mathrm{~cm}$, silica gel $60 \mathrm{~F}_{254}$, Merck), and subsequently the plate was developed with the organic phase of a $n-\mathrm{BuOH} / \mathrm{CH}_{3} \mathrm{COOH} /$ $\mathrm{H}_{2} \mathrm{O}$ (13:3:5) mixture, sprayed with anisaldehyde-sulphuric acid reagent and heated to $105^{\circ} \mathrm{C}$. Based on the observed TLC pattern, similar fractions were combined.

Semi-preparative HPLC: Fraction $1 \mathrm{~A}$ (eluted with $90 \%$ ethyl acetate and $10 \%$ methanol, $78.8 \mathrm{mg}$ ), and fraction $1 \mathrm{~B}$ (eluted with $30 \%$ ethyl acetate and $70 \%$ methanol, $255.6 \mathrm{mg}$ ), obtained by normal phase chromatography, and fractions $2 \mathrm{C}-2 \mathrm{~J}$ (eluted with a gradient of water and methanol see below), obtained with reversed phase chromatography, were separated by repeated semi-preparative HPLC. An Agilent 1200 Series HPLC with degasser, quaternary pump, automated liquid sampler, thermostatic column compartment, and diode array detector (DAD; Agilent Technologies) and a Gilson 322 HPLC with binary pump, automated liquid sampler, and UV detector (Gilson) were used for the isolation of the flavonoids. Saponins were isolated using an autoPurification system from Waters with a binary gradient module, sample manager, make-up pump, system fluidics organizer, diode array detector, and Micromass Quattro micro TQD-MS analyzer. Fractions were separated using an Apollo column (Grace; $250 \times 10 \mathrm{~mm}, 5 \mu \mathrm{m}$ ). Separation was optimized for all fractions and the following gradients were applied: solvent $\mathrm{A}$ : $\mathrm{H}_{2} \mathrm{O}+0.05 \% \mathrm{HCOOH}$; solvent $\mathrm{B}: \mathrm{CH}_{3} \mathrm{OH}+0.05 \% \mathrm{HCOOH}$, gradient fraction $1 \mathrm{~A}$ : from $50 \%$ to $70 \% \mathrm{~B}$ in $20 \mathrm{~min}$, from $70 \%$ to $95 \%$ in $2 \mathrm{~min}$; gradient fraction $1 \mathrm{~B}$ : From $15 \%$ to $67 \% \mathrm{~B}$ in $45 \mathrm{~min}$, from $67 \%$ to $100 \%$ B in $1 \mathrm{~min}$; fractions C-J: $60 \%$ B for $5 \mathrm{~min}$, from $60 \%$ to $100 \% \mathrm{~B}$ in $30 \mathrm{~min}, 100 \% \mathrm{~B}$ for $3 \mathrm{~min}$ - from $100 \%$ to $60 \% \mathrm{~B}$ in $1 \mathrm{~min}, 60 \%$ B for $5 \mathrm{~min}$. Flow rate for all gradients: $3 \mathrm{~mL} / \mathrm{min}$; $210 \mathrm{~nm}$ and $320 \mathrm{~nm}$ detection; injection volume: Fraction $1 \mathrm{~A}$ and $1 \mathrm{~B}: 450 \mu \mathrm{L}$, fraction $2 \mathrm{C}, 2 \mathrm{~F}, 2 \mathrm{G}$ and $2 \mathrm{H}$ : $600 \mu \mathrm{L}$, fraction 2 D, $2 \mathrm{E}, 2 \mathrm{I}$ and $2 \mathrm{~J}: 300 \mu \mathrm{L}$; concentration, fractions $1 \mathrm{~A}: 10 \mathrm{mg} /$ $\mathrm{mL}$ and $1 \mathrm{~B}: 30 \mathrm{mg} / \mathrm{mL}$; fractions $2 \mathrm{C}-2 \mathrm{~J}: 1.8-10 \mathrm{mg} / \mathrm{mL}$.

Structure elucidation: LC-MS analysis of the infusion of $H$. hirsuta ( $10 \mathrm{mg} / \mathrm{mL}, 80 \% \mathrm{CH}_{3} \mathrm{OH}$ ) was performed employing a Surveyor LC system equipped with a diode array detector (Thermo Fisher) and a Grace Smart column $(250 \times 4 \mathrm{~mm}, 5 \mu \mathrm{m})$. The flow rate was $1.0 \mathrm{~mL} / \mathrm{min}$, UV detection was carried out at 210, 254, 300, and $320 \mathrm{~nm}$ and the solvent program was as follows: solvent $\mathrm{A}$ : $\mathrm{H}_{2} \mathrm{O}+0.05 \% \mathrm{HCOOH}$; solvent $\mathrm{B}: \mathrm{CH}_{3} \mathrm{OH}+0.05 \% \mathrm{HCOOH}$; from $5 \%$ to $100 \% \mathrm{~B}$ in $60 \mathrm{~min}$, stay at $100 \%$ during $2 \mathrm{~min}$. The injection 
volume was $20 \mu \mathrm{L}$. The LC system was coupled to an LXQ linear ion trap (Thermo Fisher). The experimental data were recorded in the (-)-ESI mode using following conditions: Sheath gas flow: 65 arbitrary units; auxiliary gas flow: 14 arbitrary units; source voltage: $4.0 \mathrm{kV}$; ion transfer tube temperature: $350^{\circ} \mathrm{C}$; and capillary voltage: $-10 \mathrm{~V}$. Mass spectral data were recorded using data dependent scanning in the mass range $m / z$ 150-1800. For MS ${ }^{n}$ experiments an isolation width of 2 Da was used and normalized collision energy of $35 \%$ was applied. All data were acquired and processed using Xcalibur software, version 2.0. (Thermo Fisher). Accurate mass measurements were carried out using a Orbitrap mass spectrometer (Exactive, Thermo Fisher Scientific) equipped with a with an Ion Max ESI source (Thermo Fisher Scientific) in negative ion mode. Chromatographic parameters were used as described in De Paepe et al. [41].

To obtain information about the identity of the sugar moieties of the two main saponins, GC-MS analysis was performed. Compounds 1 and $\mathbf{2}$ (1.02 $\mathrm{mg}$ ) were hydrolyzed using $1 \mathrm{~mL}$ TFA ( $2 \mathrm{M}$ ) and samples were kept in an oven at $120^{\circ} \mathrm{C}$ for $5 \mathrm{~h}$.

Samples obtained from acid hydrolysis and all reference monosaccharides [D-ribose, L-rhamnose monohydrate, L-arabinose, Lxylose, D-glucuronic acid, D-galacturonic acid, D-glucose, D-fructose, L-fucose, D-galactose, and D-mannose $(100 \mu \mathrm{g})]$ were treated with pyridine and the trimethylsilylation reagent (BSTFA $+1 \%$ TMCS) and heated for $1 \mathrm{~h}$ at $70^{\circ} \mathrm{C}$. All samples were analyzed according to Medeiros and Simoneit [35] employing a Voyager GC-MS with Trace 2000 GC (Thermo Finnigan) and a Alltech Heliflex AT-5 ms capillary column with a length of $30 \mathrm{~m}$, internal diameter of $0.25 \mathrm{~mm}$ and film thickness of $0.25 \mu \mathrm{m}$ (Alltech Associates). The carrier gas He was used at a constant flow rate of $1.3 \mathrm{~mL} / \mathrm{min}$, the injector and MS source temperature were maintained at $200^{\circ} \mathrm{C}$ and $230^{\circ} \mathrm{C}$, respectively. The temperature program was as follows: start at $65^{\circ} \mathrm{C}$, hold on $65^{\circ} \mathrm{C}$ for $2 \mathrm{~min}$, temperature increase of $6^{\circ} \mathrm{C} / \mathrm{min}$ till $300^{\circ} \mathrm{C}$, hold on $300^{\circ} \mathrm{C}$ for $15 \mathrm{~min}$. The MS was operated with an ionisation energy of $70 \mathrm{eV}$. Chromatograms were recorded using selected ion monitoring (SIM), looking for prominent mass peaks at $m / z 204$ and 217. About $1 \mu \mathrm{L}$ of every sample was analyzed with a split ratio of 8 . All data were recorded and processed using Xcalibur software, version 1.0 (Thermo Fisher). The monosaccharide units present in the hydrolyzed sample were elucidated by means of the retention time of the reference sugars. The absolute configuration was done based on their most abundant configuration in nature. L-rhamnose monohydrate (19.53 min.; $20.72 \mathrm{~min}$.), L-xylose (21.08 min.; $22.02 \mathrm{~min}$.), D-glucuronic acid (25.67 min.; $26.52 \mathrm{~min}$.), D-glucose (24.29 min.; $25.80 \mathrm{~min}$.), and L-fucose (20.24 min.; 20.99 min.).

NMR Spectra were recorded in DMSO- $\mathrm{d}_{6}$ (flavonoids) and methanol- $\mathrm{d}_{4}$ (saponins) on a Bruker DRX-400 instrument, operating at $400 \mathrm{MHz}$ for ${ }^{1} \mathrm{H}$ and at $100 \mathrm{MHz}$ for ${ }^{13} \mathrm{C}$. Chemical shifts are expressed in ppm and coupling constants $(J)$ in $\mathrm{Hz}$. Specific rotation was determined on a Jasco P-2000 digital polarimeter.

28 -O- $\{[\beta$-D-xylopyranosyl $(1 \rightarrow 4)-\alpha$-L-rhamnopyranosyl $(1 \rightarrow 2)]$ [( $\beta$-D-glucopyranosyl-( $1 \rightarrow 6)]-\beta$-D-glucopyranosyl $\}$-medicagenic acid (herniariasaponin $G$ ) (1): White powder; $[\alpha]_{D}^{20} 0.99$ (c 0.35, $\mathrm{MeOH}) ;{ }^{1} \mathrm{H}-\mathrm{NMR}$ and ${ }^{13} \mathrm{C}-\mathrm{NMR}$ : See Table 1. ESI-MS m/z 1103 $\left[\mathrm{M}-\mathrm{H}^{-}, \mathrm{MS}^{2} \mathrm{~m} / z 1103[\mathrm{M}-\mathrm{H}]^{-} \mathrm{m} / z\right.$ 1085, 971, 941, 923, 501, 483, and 439, $\mathrm{MS}^{3} \mathrm{~m} / z$ 971 [M - H-132] $]^{-} \mathrm{m} / z$ 953, 809, 501, 483, $439 \mathrm{MS}^{3} \mathrm{~m} / z 941$ [M - H-162] $]^{-} \mathrm{m} / z$ 923, 747, 501, 483, $439 \mathrm{HR}$ ESIMS $m / z 1103.5289[\mathrm{M}-\mathrm{H}]^{-}$(calcd. for $\mathrm{C}_{53} \mathrm{H}_{83} \mathrm{O}_{24} 1103.5274$ ). 3-O-[ $\alpha$-L-rhamnopyranosyl-( $1 \rightarrow 3)-\beta$-D-glucuronopyranosyl]$28-0$ - $\{[\beta$-D-glucopyranosyl-( $1 \rightarrow 3)-\beta$-D-xylopyranosyl-( $1 \rightarrow 4)]-$

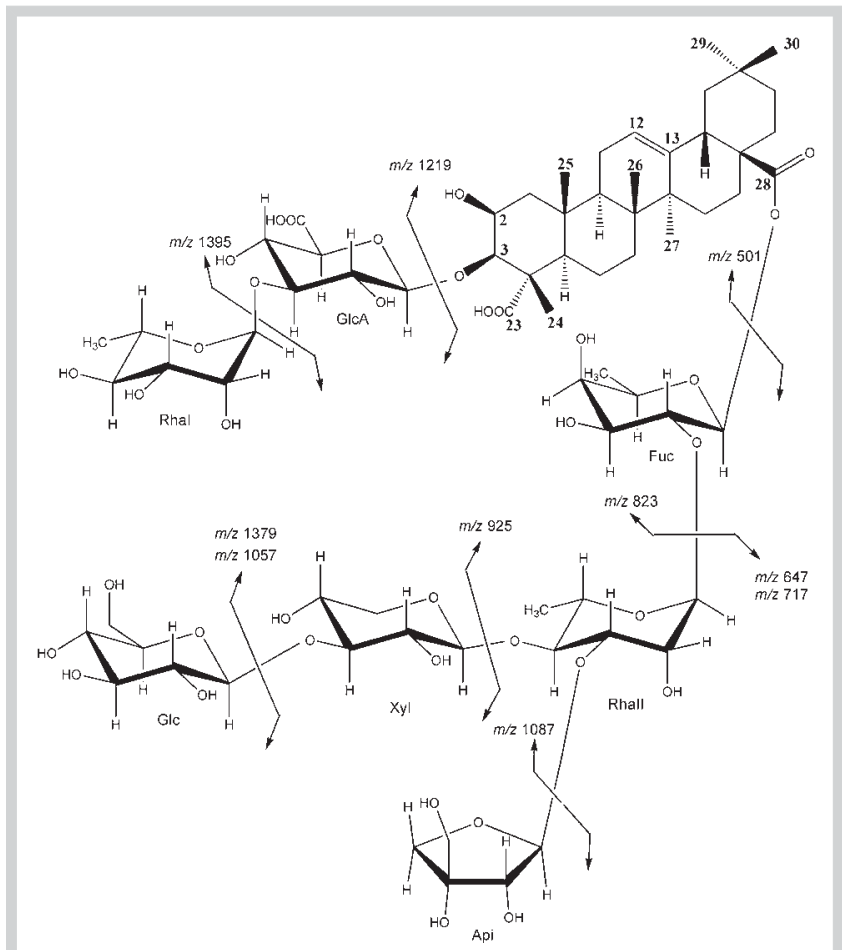

Fig. $4 \mathrm{MS}^{2}$ and $\mathrm{MS}^{3}$ fragmentations of compound 2 .

[ $\beta$-D-apiofuranosyl-( $1 \rightarrow 3)]$ - $\alpha$-L-rhamnopyranosyl- $(1 \rightarrow 2)-\beta$-Dfucopyranosyl\}-medicagenic acid (herniariasaponin H) (2): White powder; $[\alpha]_{\mathrm{D}}^{20}-35.34$ (c $\left.0.30, \mathrm{MeOH}\right) ;{ }^{1} \mathrm{HNMR}$ and ${ }^{13} \mathrm{C}-\mathrm{NMR}$ : See Table 1. ESI-MS m/z $1541\left[\mathrm{M}-\mathrm{H}^{-}, \mathrm{MS}^{2} \mathrm{~m} / \mathrm{z}\right.$ $1541[\mathrm{M}-\mathrm{H}]^{-} \mathrm{m} / z$ 1523, 1395, 1379, 1219, 1201, 1157, 1087 , 1057, 925, 823, 717, $\mathrm{MS}^{3} \mathrm{~m} / z 1395$ [M - H-146] $]^{-} \mathrm{m} / z$ 1377, 1219 , and $1157, \mathrm{MS}^{3} \mathrm{~m} / \mathrm{z} 1219$ [M - H-146-176 $]^{-} \mathrm{m} / z$ 1201, 1087, 1057 , 925, 717, 501, 483. $\mathrm{MS}^{3} \mathrm{~m} / \mathrm{z} 1087$ [M - H-146-176-132] $\mathrm{m} / \mathrm{z}$ 1069, 925, and 501, $\mathrm{MS}^{3} \mathrm{~m} / \mathrm{z} 1057$ [M - H-146-176-162] $]^{-} \mathrm{m} / \mathrm{z}$ 925, 647, 629, and 501, HR ESIMS m/z 1541.6649 [M - H] $]^{-}$(calcd. for $\mathrm{C}_{70} \mathrm{H}_{109} \mathrm{O}_{37}$ 1541.6648).

\section{Supporting information}

All ${ }^{1} \mathrm{H}$ - and ${ }^{13} \mathrm{C}-\mathrm{NMR}$ as well as 2D-NMR spectra and a HPLC profile of the infusion of $H$. hirsuta are available as Supporting Information.

\section{Acknowledgements}

The Fund for Scientific Research (FWO - Flanders, Belgium) is acknowledged for providing a fellowship to KF and SB. Financial support from FWO and the Special Fund for Research (UA-BOF-GOA) is also acknowledged.

\section{Conflict of Interest \\ $\nabla$}

The authors declare they have no conflict of interest.

\author{
References \\ 1 Knoll T. Stone disease. Eur Urol Suppl 2007; 6: 717-722 \\ 2 Moe OW. Kidney stones: pathophysiology and medical management.
} Lancet 2006; 367: 333-344 
3 Schafmayer C, Hartleb J, Tepel J, Albers S, Freitag S, Voelzke H, Buch S, Seeger M, Timm B, Kremer B, Foelsch UR, Faendrich F, Krawczak M, Schreiber S, Hampe J. Predictors of gallstone composition in 1025 symptomatic gallstones from Northern Germany. BMC Gastroenterol 2006; 6: 36

4 Stinton LM, Myers RP, Shaffer EA. Epidemiology of gallstones. Gastroenterol Clin North Am 2010; 39: 157-169

5 Tiselius HG. Epidemiology and medical management of stone disease. BJU Int 2003; 91: 758-767

6 Kum F, Mahmalji W, Hale J, Thomas K, Bultitude M, Glass J. Do stones still kill? An analysis of death from stone disease 1999 to 2013 in England and Wales. BJU Int 2016; 118: 140-141

7 Butterweck V, Khan SR. Herbal medicines in the management of urolithiasis: alternative or complementary? Planta Med 2009; 75: 10951103

8 Sakhaee K, Maalouf NM, Sinnott B. Clinical review. Kidney stones 2012: pathogenesis, diagnosis, and management. J Clin Endocrinol Metab 2012; 97: 1847-1860

9 Spernat D, Kourambas J. Urolithiasis - medical therapies. BJU Int 2011; 108: 9-13

10 Das I, Verma S. Human stones: Dissolution of calcium phosphate and cholesterol by edible plant extracts and bile acids. Journal Sci Indust Res 2008; 67: 291-294

11 Lambou-Gianoukos S, Heller SJ. Lithogenesis and bile metabolism. Surg Clin North Am 2008; 88: 1175-1194

12 Konikoff FM. Gallstones - approach to medical management. MedGenMed 2003; 5: 8

13 Portincasa P, Ciaula AD, Bonfrate L, Wang DQ. Therapy of gallstone disease: What it was, what it is, what it will be. World J Gastrointest Pharmacol Ther 2012; 3: 7-20

14 Sur R, Masterson J, Palazzi K. Impact of statins on nephrolithiasis in hyperlipidemic patients: a 10-year review of an equal access health care system. Clin Nephrol 2013; 79: 351-355

15 Gürocak S, Küpeli B. Consumption of historical and current phytotherapeutic agents for urolithiasis: A critical review. J Urol 2006; 176: 450455

16 Atmani F, Slimani Y, Mimouni M, Aziz M, Hacht, B, Ziyyat A. Effect of aqueous extract from Herniaria hirsuta L. on experimentally nephrolithiasic rats. J Ethnopharmacol 2004; 95: 87-93

17 Settaf A, Labhal A, Cherrah Y, Slaoui A, Hassar M. Herniaria hirsuta dissout les calculs biliaires cholestéroliques. Espérance Médicale 1999; 6: 79-82

18 Eddouks M, Maghrani M, Lemhadri A, Ouahidi ML, Jouad H. Ethnopharmacological survey of medicinal plants used for the treatment of diabetes mellitus, hypertension and cardiac diseases in the south-east region of Morocco (Tafilalet). J Ethnopharmacol 2002; 82: 97-103

19 Mbark AN, Charouf Z, Wray V, Nimtz M, Schopke T. Monodesmosidic saponins from Herniaria hirsuta. Pharmazie 2000; 55: 690-692

20 Bundesministerium für Gesundheit. Österreichisches Arzneibuch, Amtliche Ausgabe 2010. Wien: Verlag Österreich; 2010: 335-336

21 Charrouf Z, NaitMbark A, Guillaume D, Leroy Y, Kol O. Herniaria saponin $B$, a novel triterpenoid saponin from Herniaria fontanesii. Adv Exp Med Biol 1996; 405: 241-245

22 Mbark AN, Charrouf Z, Wieruszeski JM, Leroy Y, Kol O. Herniaria saponin A, a novel saponin from Herniaria fontanesii. Nat Prod Lett 1995; 6: 233-240
23 MBark AN, Guillaume D, Kol O, Charrouf Z. Triterpenoid saponins from Herniaria fontanesii. Phytochemistry 1996; 43: 1075-1077

24 Freiler M, Reznicek G, Jorenitsch J, Kubelka W, Schmidt W, SchubertZsilavecz M, Haslinger E, Reiner J. New triterpene saponins from Herniaria glabra. Helv Chim Acta 1996; 79: 385-390

25 Schroder H, Schubert-Zsilavecz M, Reznicek G, Cart J, Jurenitsch J, Haslinger E. A triterpene saponin from Herniaria glabra. Phytochemistry 1993; 34: 1609-1613

26 Reznicek G, Cart J, Korhammer S, Kubelka W, Jurenitsch J, Halsinger E. The first two spectroscopically confirmed saponins from Herniaria glabra L. Pharmazie 1993; 48: 450-451

27 Freiler M, Reznicek G, Schubert-Zsilavecz M, Kubelka W. Structures of triterpene saponins from Herniaria glabra. Sci Pharm 1996; 64: 359-365

28 Wagner H, Bladt S, Zgainski E. Flavonoid-Drogen. In: Drogenanalyse. Dünnschichtchromatographische Analyse von Arzneidrogen. Berlin, Heidelberg, New York: Springer; 1983: 176-177

29 Wagner H, Bladt S, Zgainski E. Cumarin-Drogen. In: Drogenanalyse. Dünnschichtchromatographische Analyse von Arzneidrogen. Berlin, Heidelberg, New York: Springer; 1983: 149-157

30 Mbark A, Guillaume D, Cherrah Y, Wieruszeki J, Ricart G, Charrouf Z. An acylated isorhamnetin glycoside from Herniaria fontanesii. Phytochemistry 1996; 41: 989-990

31 Czygan FC, Frohne D, Hiller K, Höltzel C, Nagell A, Pachaly P, Pfänder HJ, Willuhn G, Buff W. Herniariae herba - Rupturewort. In: Wichtl M, ed. Herbal Drugs and Phytotherapeuticals. A Handbook for Practice on a scientific Basis, 3th ed. Boca Raton: CRC Press; 2004: 289-291

32 Dictionary of natural Products on DVD, Version 24: 2. Boca Raton: CRC Press; 2015

33 Van Dooren I, Faouzi M, Foubert K, Theunis M, Pieters L, Cherrah Y, Apers $S$. Cholesterol lowering effect in the gall bladder of dogs by a standardized infusion of Herniaria hirsuta L. J Etnopharmacol 2015; 169: 69-75

34 Pollier J, Morreel K, Geelen D, Goossens A. Metabolite profiling of triterpene saponins in Medicago trunculata hairy roots by liquid chromatography fourier transform ion cyclotron resonance mass spectrometry. J Nat Prod 2011; 74: 1462-1476

35 Medeiros PM, Simoneit BR. Analysis of sugars in environmental samples by gas chromatography-mass spectrometry. J Chromatogr A 2007; 1141: $271-278$

36 Tan N, Zhou J, Zhao S. Advances in structural elucidation of glucuronide oleanan-type triterpene carboxylic acid 3,28-O-bidesmosides (19621997). Phytochemistry 1999; 52: 153-192

37 Agrawal P. NMR spectroscopy in the structural elucidation of oligosaccharides and glycosides. Phytochemistry 1992; 31: 3307-3330

38 Borges R, Tinoco L, Filho J, Barbi N, da Silva A. Two new oleanan e saponins from Chicocca alba (L.) Hitch. J Braz Chem Soc 2009; 20: 17381741

39 Felser C, Schimmer O. Flavonoid glycosides from Alchemilla speciosa. Planta Med 1999; 65: 668-670

40 Böttger S, Melzig M. Triterpenoid saponins of the Caryophyllaceae and Illebraceae family. Phytochem Lett 2011; 4: 59-68

41 De Paepe P, Servaes K, Noten B, Diels L, De Loose M, Van Droogenbroeck B, Voorspoels $S$. An improved mass spectrometric method for identification and quantification of phenolic compounds in apple fruits. Food Chem 2013; 136: 368-375 